\title{
Unusual Neurological Complications of Lumbar Myelography with Dimeglumine Iocarmate (Dimer X)
}

\author{
Dr Bektaş Açikgöz, ${ }^{1}$ Dr Selçuk Palaoğlu, ${ }^{1}$ Dr Erdener Timurkaynak, ${ }^{2}$ \\ Dr Şefik Ünlü ${ }^{3}$ \\ ${ }^{1}$ Instructor in Neurosurgery, ${ }^{2}$ Associate Professor of Neurosurgery, ${ }^{3}$ Professor of \\ Neurosurgery, Gülhane Military Academy, School of Medicine, Ankara, Turkey
}

\section{Summary}

In this report two unusual and serious neurological complications of dimeglumine iocarmate (Dimer $X$ ) myelography is presented. One patient became paraplegic six hours after myelography, and the other was mute for 24 hours after having generalised convulsions. The reasons are discussed.

Key words: Dimer $X$ myelography; Paraparesis; Generalised convulsions; Mutism.

\section{Introduction}

In the early 1930s iondinated oils were used for their good contrast in myelography but there were difficulties in filling nerve roots sheaths and showing any arachnoid adhesions thus these agents have in many centres been replaced with water-soluble contrast agents (Ahlgren, 1975; Danzinger, 1973; Grainger, 1971; Jensen, 1978; Junck, 1983). In the literature it appears that from the 1970's water-soluble contrast agents are preferred (Ahlgren, 1975; Danzinger, 1973; Grainger, 1971; Gensette, 1971; Jensen, 1978).

The clinical use of the water-soluble contrast fluid Dimer X (Dimeglumine iocarmate) became common after the reports of Grainger et al. (1971), Gonsette (1971) and Occleshaw (1971).

Two patients with rare and serious complications of myelography where Dimer X was used are presented:

\section{Case 1:}

A 20-year-old male patient was admitted to our hospital with back and bilateral leg pains. Neurological examination showed that the straight leg raising test was restricted to $30^{\circ}$ on the right, and to $45^{\circ}$ on the left; the right anterior tibialis muscle was weak (3/5); hypoesthesia of left leg; scoliosis concave to the right. The only abnormality on plain x-rays was the scoliosis. Myelography was performed after premedication with $10 \mathrm{mg}$ of diazepam I.M.; $10 \mathrm{ml}$ of Dimer X 

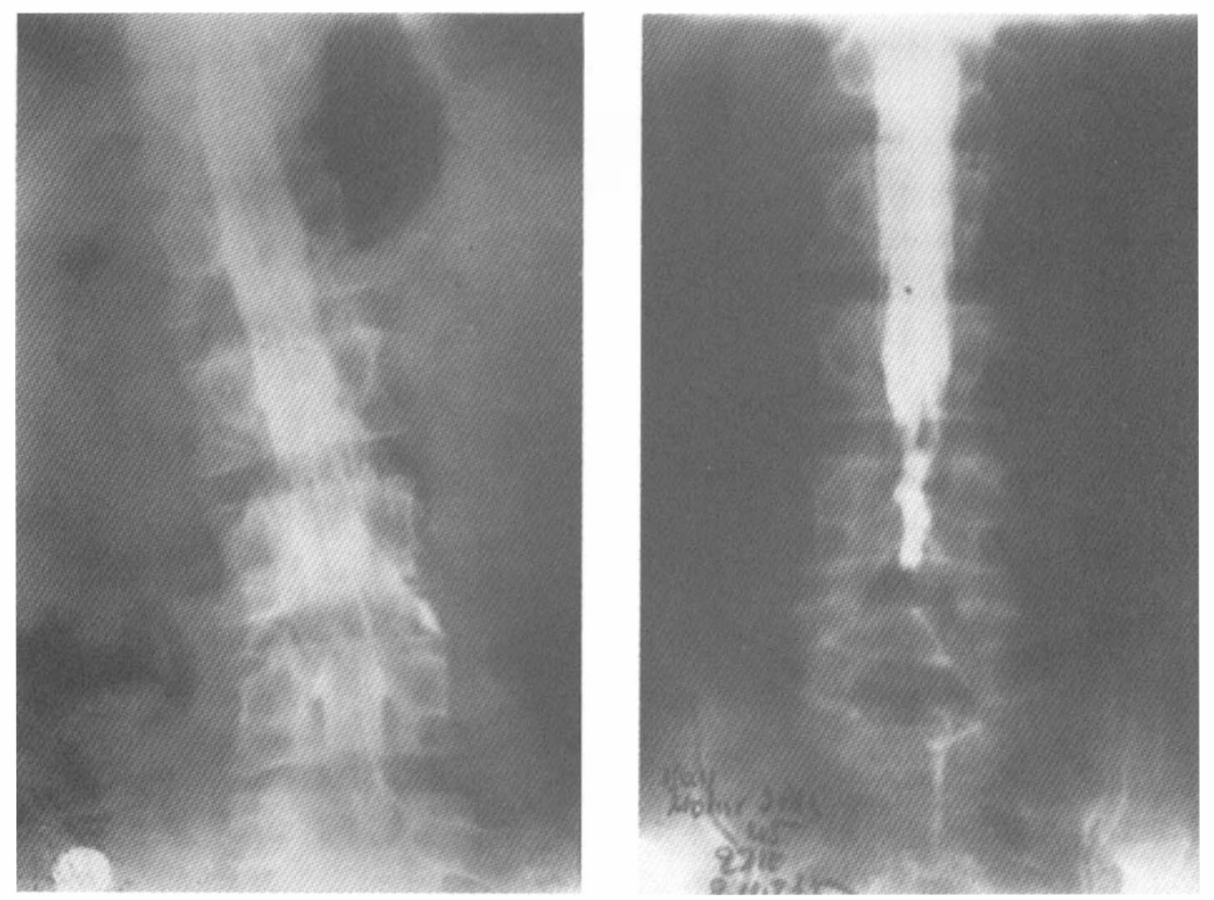

Figure 1. Myelogram, anteroposterior view, L4/5 total block. Contrast material came closer to the conus.

Figure 2. Myelogram, anteroposterior view, L3/4 total block. Contrast material extended to the medullary cone.

was injected into the subarachnoid space at the L2/3 level. A total block was seen at the L4/5 level. Contrast material reached the conus medullaris (Fig. 1). After myelography a sudden paraparesis developed. Steroids were given intravenously and 30 minutes later the paraparesis improved. But 6 hours later the patient became paraplegic, with anaesthesia below the level of T10, areflexic and had urinary incontenence. He was operated on immediately, a laminectomy of L2 being performed. The conus medullaris was oedematous; there was no evidence of an epidural or subdural hematoma. A centrally protruded disc at the L4/5 level was excised. From the first postoperative day, motor function improved dramatically, full neurological recovery ensued.

\section{Case 2:}

A 45-year-old patient was admitted to hospital because of lumbar and right leg pain. He had been operated on in 1976 for a left lumbar 4/5 disc protrustion but still had symptoms after lifting heavy objects. The straight leg raising test was restricted to $45^{\circ}$ on the left side, the left tibialis anterior muscle was weak, the Achilles reflex was absent. EMG showed lumbar 5 radicular pathology. Myelography was carried out after premedication with $10 \mathrm{mg}$ diazepam I.M.; 
$10 \mathrm{ml}$ of Dimer X was injected into subarachnoid space at L2/3 level. A total block was seen at L3/4 level. The contrast material came into contact with the conus medullaris (Fig. 2). Twenty four hours after myelography generalised convulsions occurred, and the patient was mute for 24 hours. He was given antiepileptic and antioedematous drugs, and a day later his condition improved.

\section{Discussion}

Paraparesis may rarely develop after Dimer X myelography (Kühner, 1977; Perrigot, 1976). Dimer $X$ which contains $28 \%$ iodine, dissolves in the cerebrospinal fluid, resorbs in 6-8 hours and leaves the body in 24 hours (Danzinger, 1973).

Water-soluble contrast agents are preferred for myelography in lumbar spine pathology where there is compression of cauda equina roots, especially from disc herniation (Krüger, 1977). In the two patients described, Dimer X was used as the contrast material because the presenting features were radicular symptoms leading to suspection of lumbar $4 / 5$ disc herniation.

It is reported that clonic jerks may be seen after the use of Dimer X (Ahlgren, 1975; Eastwood, 1978; Irstam, 1975). We have also seen this in some of our patients. These clonic jerks can be reduced after premedication with diazepam (Irstam, 1975; Krüger, 1977). Our patients had diazepam premedication.

Sinclair and Kitchie (1972) found that meningeal irritation is directly related to the bore of the needle. In both of our patients we used 22 gauge needles. One of the advantages of the water-soluble contrast material is that it can be injected through fine bore needles.

It was suspected that the cause of paraparesis after Dimer X myelography was directly related to the contrast material coming in contact with upper cauda equina fibres and the conus medullaris (Eastwood, 1978; Kühner, 1977; Perrigot; 1976). Gensette (1971) showed in an experimental study in pigs that the injection of Dimer $\mathrm{X}$ into the subarachnoid space causes vasodilatation, oedema and inflammation which subside completely in 48 hours. In the present cases, because of the total block in the lower lumbar region contrast material came in contact with the conus medullaris. In the first case conus medullaris symptoms and signs were seen 6 hours after myelography and the medullary cone was found to be oedematous at operation; this was also seen by Gonsette (1971).

High dosage of the contrast medium may also be a factor, but in the literature different dosages have been reported (Kühner, 1977; Perrigot, 1976). Although the dosage was reported as $8 \mathrm{ml}$ by Perrigot et al. (1976), it was either $10 \mathrm{ml}$ or $5 \mathrm{ml}$ in Kühner's (1977) cases.

Ahlgren (1975) and Irstam (1975) have reported that clonic convulsions may result from contact of Dimer X with the medullary cone. Irstam (1975) noted that EEG spikes were seen after contact of the contrast material with the conus medullaris.

After Dimer X myelography spikes were seen in the first and third hours and the EEG studies were normal after 24 hours (Irstam, 1975). In a study by Irstam (1975) Dimer X reached the basal, suprasellar, callosal and quadrigeminal cisterns and sylvian fissure from the lumbar region in 3 hours and spread over surface of the brain in 24 hours. According to Irstam (1975), Guerbert had 
stated that the contrast material resorbed locally in some parts of the subarachnoid space. In our second patient generalised convulsions were seen 24 hours after myelography and mutism occurred, which subsided with antioedematous therapy. This is in accord with the reasons given by Guerbert (1975).

We believe that new non-ionic water-soluble contrast medias are much safer for myelography (and for radiculography) compared with the ionic polarised water soluble contrast media.

\section{References}

Ahlgren P 1975 Amipaque myelography, the side effects compared with Dimer X. Neuroradiology 9:197-202.

DANZiNGer J, BLoch S 1973 A clinical evaluation of Dimer X in lumbar radiculography. Clinical Radiology 24:231-234.

EAstwood JB, PARKer B, ReID BR 1978 Bilateral central fracture-dislocation of hips after myelography with meglumine iocarmate (Dimer X). British Medical Journal 1(6114):692-693.

Grainger JB, Gumpert J, Sharpe DM, et al. 1971 Water soluble radiculography. A clinical trial of Dimer X. A new contrast medium. Clinical Radiology 22:57-62.

GONSETTE R 1971 An experimental and clinical assessment of water-soluble contrast medium in neuroradiology. A new medium-Dimer X. Clinical Radiology 22:44-56.

IRSTAM L, SEYYDEN U 1975 Side effects after lumbar myelography with dimeglumine iocarmate (Dimer X). Acta Radiologica Diagnosis 16:449-462.

JENSEN TS, HEIN O 1978 Intraspinal arachnoiditis and hydrocephalus after lumbar myelography using methylglucamine iocarmate. J Neurology Neurosurgery Psychiatry 41(2):108-112.

JUNCK L., MARSHALl WH 1983 Neurotoxicity of radiological agents. Annals of Neurology 13:469484.

KRÜGER J, WILD K, HACKER H 1977 Wie gefahrlos ist die lumbosakrale myelographie mit wasserlöslichen kontrastmitteln? Deutsche Medizinische Wochenschrift 102(10):342-345.

KüHNer A, HAgenlocher HU, Ciba K, et al. 1977 Akutes kaudasyndrom nach Dimer X in lumbar radiculography. Neurochirurgia 20:216-221.

OCCLESHAW JV, HolYLAND JN 1971 Comparative study of the effects of Conray 280 and Dimer $X$ in lumbar radiculography. British Journal of Radiology 44:946-948.

Perrigot M, Pierrot-Deseilligny E, Bussel B, et al. 1976 Paralysies survenues dans les suites d'une radiculographie au Dimer X. La Nouvelle Presse Medicale 5(17):1120-1122.

Sinclair DJ, Ritchie GW 1972 Morbidity in post-myelogram patients. A survey of 100 patients. Journal of Canadian Association of Radiologists 23:278-283. 